\title{
TU/e EN⿴HONE

\section{Solute rejection in the presence of a deposited layer during ultrafiltration}

\section{Citation for published version (APA):}

Oers, van, C. W., Vorstman, M. A. G., \& Kerkhof, P. J. A. M. (1995). Solute rejection in the presence of a deposited layer during ultrafiltration. Journal of Membrane Science, 1995(107), 173-192.

https://doi.org/10.1016/0376-7388(95)00116-T

DOI:

10.1016/0376-7388(95)00116-T

Document status and date:

Published: 01/01/1995

\section{Document Version:}

Publisher's PDF, also known as Version of Record (includes final page, issue and volume numbers)

\section{Please check the document version of this publication:}

- A submitted manuscript is the version of the article upon submission and before peer-review. There can be important differences between the submitted version and the official published version of record. People interested in the research are advised to contact the author for the final version of the publication, or visit the $\mathrm{DOI}$ to the publisher's website.

- The final author version and the galley proof are versions of the publication after peer review.

- The final published version features the final layout of the paper including the volume, issue and page numbers.

Link to publication

\section{General rights}

Copyright and moral rights for the publications made accessible in the public portal are retained by the authors and/or other copyright owners and it is a condition of accessing publications that users recognise and abide by the legal requirements associated with these rights.

- Users may download and print one copy of any publication from the public portal for the purpose of private study or research.

- You may not further distribute the material or use it for any profit-making activity or commercial gain

- You may freely distribute the URL identifying the publication in the public portal.

If the publication is distributed under the terms of Article 25fa of the Dutch Copyright Act, indicated by the "Taverne" license above, please follow below link for the End User Agreement:

www.tue.nl/taverne

Take down policy

If you believe that this document breaches copyright please contact us at:

openaccess@tue.nl

providing details and we will investigate your claim. 


\title{
Solute rejection in the presence of a deposited layer during ultrafiltration
}

\author{
C.W. van Oers *, M.A.G. Vorstman, P.J.A.M. Kerkhof \\ Department of Chemical Process Technology, Eindhoven University of Technology, P.O. Box 513, 5600 MB Eindhoven, Netherlands
}

Received 8 June 1994; accepted 4 April 1995

\begin{abstract}
During ultrafiltration deposited layers are often formed on the membrane surface. These layers not only reduce the volumetric flux through the membrane, but also may influence the rejection of other solutes in the feed. In the present paper we will show that besides an increase in the rejection, a decrease in rejection may also occur, which can completely alter the aimed selectivity of the separation process. The influence of deposited layers has been studied experimentally by two types of depositing components: silica sol and the protein BSA. In the presence of a relatively open silica deposit a strong drop in the rejection of PEG and dextran was found compared to the rejection on a clean membrane. For thick deposit layers the rejection even decreased to zero, thus resulting in a total permeation of a normally partially rejected solute. On the other hand an increase in PEG rejection occurred in the presence of a BSA deposit. Due to the compressibility of the protein deposit the highest rejections were measured at the highest pressures. The effects were the most pronounced at the isoelectric point of BSA. A model is presented to describe the underlying phenomena.
\end{abstract}

Keywords: Deposit; Rejection; Selectivity; Fractionation; Ultrafiltration

\section{Introduction}

During the purification of process liquids or waste waters by ultrafiltration deposited layers are often formed on the membrane surface. In the literature the deposit formation is often referred to as gel layer formation. These layers not only reduce the volumetric flux through the membrane, but also may influence the rejection of other solutes in the feed. In the present paper we will show that both an increase or decrease in the rejection may occur, which can completely alter the aimed selectivity of the separation process.

\footnotetext{
* Corresponding author. Present address: Akzo Nobel Central Research, P.O. Box 9300, 6800 SB Arnhem, Netherlands.

Many types of components may form a deposit layer during membrane filtration; protein is most extensively studied in the literature. A number of studies has dealt with the influence of protein on the rejection behaviour of other solutes [1-10]. All of them report an increase in rejection of the accompanying solutes compared to the rejection without protein present ( $[1-4]$ have been discussed in more detail by Mochizuki and Zydney, [5] ). Besides an increase in the rejection Papamichael and Kula [6] also reported a decrease in PEG rejection in the presence of BSA at low fluxes and high BSA concentrations. The authors attributed the lowering of the PEG rejection to the stripping of water bonded to the PEG molecule by BSA, in that way reducing the effective size of the PEG molecule. 
During the filtration of proteins several phenomena play a role in influencing the flux and/or the rejection of other solutes present in these solutions: osmotic pressure, adsorption on the membrane surface, deposition on the membrane surface and compression of the deposition layer as a function of the solution environment [7]. Busby and Ingham [8,9] have studied the separation of PEG and BSA solutions by means of diafiltration. They concluded that the increase in PEG rejection in the presence of BSA was due to irreversible adsorption on the polysulfone PM30 membranes (Amicon), because an overnight treatment with trypsin was necessary to restore the flux and rejection. In the case of the regenerated cellulose membrane YM30 the flux after filtration was not affected by the protein filtration, however the PEG rejection showed an increase from of 0.2 to 0.4 after BSA filtration and this effect was reversed by trypsin treatment.

Mochizuki and Zydney have separately characterized the rejection behaviour of protein adsorbed membranes [4] and the influence of the presence of a deposited BSA layer on the membrane surface [5] using polydisperse dextrans with the dextran molecular weight distribution evaluated using gel permeation chromatography. Microfiltration membranes were used, which without treatment with proteins showed no rejection for the dextran molecules. They showed that both adsorption and deposition on the polyethersulfone membranes caused a rise in the dextran rejection. In a recent study Lentsch [10] observed similar effects for PEG20 000 rejection in combination with BSA on a polysulfone membrane.

According to Mochizuki and Zydney [5] both the actual rejection of dextran and the hydraulic resistance of the BSA deposit are minimum at the isoelectric point of BSA ( $\mathrm{pH}=4.7)$. These effects on hydraulic permeability and actual rejection are consistent, but they contrast with the maximum in hydraulic resistance at the isoelectric point found by Suki et al. [12]. The rejecting behaviour and the hydraulic resistance of the BSA deposit was also reported to be a function of the ionic strength of the solution $[5,13]$.

Nakao et al. [1] reported an increase in solute rejection with increasing pressure, which they attributed to the compressibility of the ovalbumin and polyvinyl alcohol deposits. The same type of effects have been measured for dextran in the presence of BSA deposits $[5]$.
Kerkhof and Schoutens [11] have shown that during the filtration of enzymes an increase in rejection of a coloured component occurred with increasing pressure, which was ascribed to the formation of a secondary membrane by the enzymes.

To contribute to a more complete understanding of the ways a deposit layer may influence the rejection of accompanying solutes, two types of depositing components have been chosen, silica sol and the protein BSA. During the filtration of silica sol only the formation of a silica deposit is involved. Two types of silica sols have been studied in combination with either PEG or dextran. The rejection of PEG has also been determined in combination with BSA. In our experiments the influence of adsorption and deposition is considered separately. The influence of the $\mathrm{pH}$ on the rejection of PEG is tested.

First, a theoretical description of the influence of the presence of a deposit layer on the solute rejection will be presented. Next, the procedure for the series of experiments will be presented. The influence of deposition during silica filtration on the rejection of PEG and dextran will be discussed, followed by the results of the influence of BSA adsorption and deposition on the PEG rejection.

\section{Theory}

Jagur-Grodzinski and Kedem [14] derived an equation for the actual rejection $R_{\mathrm{act}}=1-C_{\mathrm{p}} / C_{\mathrm{m}}$, for a two layer reverse osmosis membrane. Nakao at al. [1] has used this equation for the description of the increase in rejection in the presence of a deposit during ultrafiltration. In that case the two layer system consisted of the deposit in combination with a membrane. The equation for the actual rejection is extended below to obtain an expression for the observed rejection. Use is made of a description based on the hindered transport model [15] instead of non-equilibrium thermodynamics [14].

We consider the case that a liquid that has to be filtered contains two solutes; one that is forming a deposit or a gel layer (and is totally rejected by the membrane) and another one that would (partially) permeate through the membrane if present as a single solute. The permeating component meets three transport layers in series: the polarization layer (concentration denoted by $C$ ), the deposit layer (concentration in 


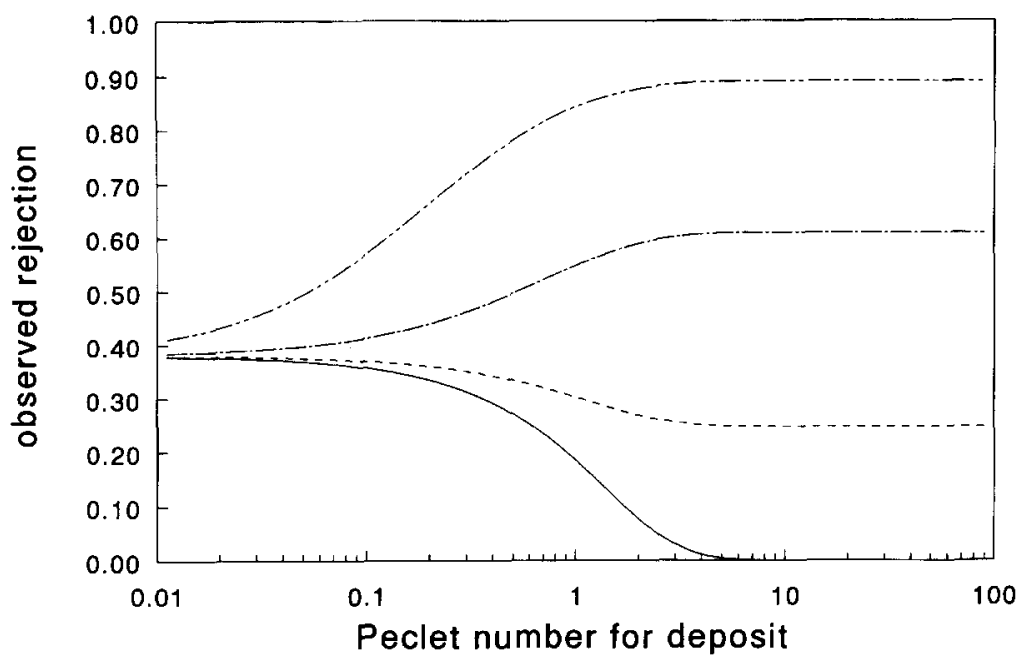

Fig. 1. Calculated observed rejection as a function of the $P e$-number of the deposit layer for various values of the exclusion of the deposit: $\phi_{\mathrm{dep}}=1(-), 0.2(--), 0.05(\cdots)$ and $0.01(\cdots) . P e_{\mathrm{m}}=0.5, v=5 \mu \mathrm{m} \mathrm{s}^{-1}, k=2 \mu \mathrm{m} \mathrm{s}^{-1}$ and $\phi_{\mathrm{m}}=0.05$.

the pore liquid $\left.C^{\prime}\right)$ and the membrane $\left(C^{\prime \prime}\right)$. At each interface between these three layers equilibrium is assumed, determined by the exclusion factor $\phi$ :

$$
\begin{aligned}
& C_{\mathrm{r} / \mathrm{dep}}^{\prime} / C_{\mathrm{r} / \mathrm{dep}}=\phi_{\mathrm{dep}} \\
& C_{\mathrm{dep} / \mathrm{m}}^{\prime \prime} / C_{\mathrm{dep} / \mathrm{m}}^{\prime}=\phi_{\mathrm{m}} / \phi_{\text {dep }} \\
& C_{\mathrm{m} / \mathrm{p}}^{\prime \prime} / C_{\mathrm{p}}=\phi_{\mathrm{m}}
\end{aligned}
$$

Eq. (1b) follows from Eqs. (1a) and (1c) for reasons of thermodynamic consistency.

The transport in the membrane is described by Deen [15]:

$v K_{\mathrm{c}} C^{\prime \prime}-\frac{\varepsilon}{\tau} K_{\mathrm{d}} D \frac{\mathrm{d} C^{\prime \prime}}{\mathrm{d} z}=v C_{\mathrm{p}}$

and the equation for the deposit layer is obtained by replacing $C^{\prime \prime}$ by $C^{\prime} . K_{\mathrm{c}}$ and $K_{\mathrm{d}}$ in the deposit layer will be unity if no exclusion takes place at the retentate/ deposit interface, if so $\phi_{\mathrm{dep}}=1$. If exclusion occurs $K_{\mathrm{c}}$ may reach a maximum value of 2 , whereas $K_{\mathrm{d}}$ will decrease with decreasing value of the exclusion factor $\phi$. These transport equations for deposit layer and membrane can be integrated over the thickness of the respective layers under the assumption that the properties of the layers are constant over the thickness (not a function of the 'solid' pressure that increases in the direction towards the membrane). Combining these equations with the well-known equation for the concentration difference over the polarization layer derived from the film model, we obtain for the observed rejection, $R_{\mathrm{obs}}=1-C_{\mathrm{p}} / C_{\mathrm{b}}$ :

$$
\begin{gathered}
R_{\text {obs }}=1-\left(1+\frac{1}{\phi_{\mathrm{r} / \mathrm{dep}}} \mathrm{e}^{-\frac{v}{k}}\left(1-\phi_{\mathrm{r} / \mathrm{dep}}+\frac{\phi_{\mathrm{r} / \mathrm{dep}}}{\phi_{\mathrm{m}}} \mathrm{e}^{-P e_{\text {dep }}}\right.\right. \\
\left.\left.\left(1-\frac{\phi_{\mathrm{m}}}{\phi_{\mathrm{r} / \mathrm{dep}}}-\left(1-\phi_{\mathrm{m}}\right) \mathrm{e}^{-P e_{\mathrm{m}}}\right)\right)\right)^{-1}
\end{gathered}
$$

in which $P e_{\text {dep }}=K_{\mathrm{c}} v \delta_{\mathrm{dep}} /\left(\varepsilon_{\mathrm{dep}} K_{\mathrm{d}} D / \tau\right)$ and $P e_{\mathrm{m}}$ are the Peclet numbers for the deposit layer and the membrane, respectively.

Values of the observed rejection according to Eq. (3) are presented in Fig. 1 as a function of $P e_{\text {dep }}$ for $v / k=1.5, \phi_{\mathrm{m}}=0.05$ and $P e_{\mathrm{m}}=0.5$ and for various values of the exclusion factor of the deposit layer, $\phi_{\mathrm{dep}}$. The increase in the $P e_{\text {dep }}$ can be considered as an increase in the thickness of the deposit layer, assuming that the other parameters in $P e_{\text {dep }}$ are constant (see definition of $P e_{\text {dep }}$ ). Two asymptotic values can be distinguished for very thin and for very thick layers (low and high $P e_{\text {dep }}$ values). The limiting case for very thin layers equals the rejection encountered in the absence of a deposit layer. The asymptotic value for thick deposit layers can be easily derived from Eq. (3) by setting $P e_{\text {dep }}$ equal to infinity.

If the exclusion by the deposit layer is stronger than by the membrane $\left(\phi_{\text {dep }}<\phi_{\mathrm{m}}\right.$ or more exactly $\left.\phi_{\text {dep }}<\phi_{\mathrm{m}} /\left(1-\left(1-\phi_{\mathrm{m}}\right) \mathrm{e}^{-P e_{\mathrm{m}}}\right)\right)$, the deposit layer can be considered as an extension of the membrane and 
if the deposit is thick it will fully overtake the sieving action from the membrane. In this case the concentration gradient in the deposit layer is negative as it is in the membrane. The observed rejection of such a deposit will be higher than that for a clean membrane (see Fig. 1).

An opposite effect is observed if the deposit is more open than the membrane $\left(\phi_{\mathrm{dep}}>\phi_{\mathrm{m}}\right)$. From the limiting case of $\phi_{\text {dep }}=1$ which reads:

$$
\begin{aligned}
& R_{\mathrm{obs}}=1-\left(1+\mathrm{e}^{-\frac{v}{k}} \frac{1}{\phi_{\mathrm{m}}} e^{-P e_{\mathrm{dep}}}\left(1-\phi_{\mathrm{m}}\right)\right. \\
& \left.\left(1-\mathrm{e}^{-P e_{\mathrm{m}}}\right)\right)^{-1}= \\
& 1-\left(1+\frac{1}{\phi_{\mathrm{m}}} \mathrm{e}^{-\left(\frac{u}{k}+P e_{\mathrm{dep}}\right)}\right. \\
& \left.\left(1-\phi_{\mathrm{m}}\right)\left(1-\mathrm{e}^{-P_{e_{\mathrm{m}}}}\right)\right)^{-1}
\end{aligned}
$$

it can be seen that the exponential concentration increase in the polarization layer and in the deposit layer are additional quantities. The concentration in the deposit layer increases in the direction towards the membrane and the concentration profile in the deposit layer may be seen as an extension of the one in the polarization layer. This may lead to very high concentrations near the membrane (if $\phi_{\text {dep }}=1$ then $C_{\mathrm{m}}=C_{\mathrm{p}}$ / $\left.\left(1-R_{\text {act }}\right)\right)$. If the deposit layer thickness increases the solute diffusion back to the bulk will decrease until finally hardly any solute returns to the bulk. The concentration at the deposit/membrane interface will increase until the permeate concentration becomes so high that all solute that enters the deposit layer by convection will pass through the membrane; $C_{\mathrm{p}}$ will equal $C_{\mathrm{b}}$ and $R_{\mathrm{obs}}$ approaches zero. For values of $\phi_{\mathrm{dep}}$ smaller than one but clearly larger than $\phi_{\mathrm{m}} /(1-(1-$ $\left.\left.\phi_{\mathrm{m}}\right) \mathrm{e}^{-P e_{\mathrm{m}}}\right)$, the asymptotic value of the rejection for thick deposit layers will be lower than those for a clean membrane. Although $R_{\text {obs }}$ does not approach zero, the rejection will still decrease due to the formation of such a deposit. In literature $[14,16]$ it was already indicated that reversal of an asymmetric membrane with its more open side towards the retentate causes a decrease in rejection compared to normal operation. This phenomenon is similar to the effect of the presence of an open deposit layer on the more compact membrane surface.
Ridgway [17] has demonstrated the increase in salt passage through reverse osmosis membranes in the presence of a foulant layer. He ascribed it to the increase in concentration polarization of the salt in the unstirred layer near the surface. This is in line with the phenomena described above for an open deposit layer.

The curve for $\phi_{\mathrm{r} / \mathrm{dep}}=0.05$, which is equal to the value chosen for $\phi_{\mathrm{m}}$, can be considered as the variation of the observed rejection of one homogeneous membrane with a variable thickness (since $\phi_{\text {dep }}$ ' $\left.\phi_{\mathrm{m}}=1\right)$. In this case $P e_{\text {dep }}$ and $P e_{\mathrm{m}}$ are additional quantities.

The asymptotic values of the observed rejection for thick deposit layers will only be reached if the deposit layer formation is not limited by a too low flux value caused by a high osmotic pressure of the solute at the membrane interface. In order to calculate the combined effect the mass transfer coefficient for the deposit forming component, deposit resistance and porosity should be known.

\section{Experimental}

\subsection{Model components}

Experiments were performed with a number of aqueous systems, combinations of different depositing components and solutes: silica/PEG, silica/dextran and BSA/PEG. Use was made of poly (ethylene glycol): PEG3400 (Aldrich) and PEG6000 (Serva) with a molecular weight of 3400 and $6000 \mathrm{Da}$, respectively and dextranT40 (MW=39000 Da, Sigma Chemicals). The types of silica sol used for the experiments were Aerosil 200 (Degussa) and Ludox HS-40 (Dupont), respectively, a dry powder and an alkali stabilized 40 wt $\%$ silica suspension with a $\mathrm{SiO}_{2} / \mathrm{Na}_{2} \mathrm{O}$ ratio of 95 . Both silica sols have a particle diameter of approximately $12 \mathrm{~nm}$, but Ludox HS-40 tends to form more concentrated deposit layers.

Bovine Serum Albumin, BSA, was purchased from Sigma Chemicals (Fraction V). The filtration experiments have been performed at two $\mathrm{pH}$ values, 7.4 and 4.5. The BSA was dissolved in a salt solution with an ionic strength of $0.15 \mathrm{kmol} \mathrm{m}^{-3}$. At that ionic strength the isoelectric point of $\mathrm{BSA}$ is equal to $\mathrm{pH}=4.7$ [7]. The saline solution at $\mathrm{pH}=7.4$ consisted of a phosphate buffer with additional $\mathrm{NaCl}$ and at $\mathrm{pH}=4.7$ the solution 
contained either an acetate buffer or $\mathrm{NaCl}$ and $\mathrm{HCl}$. $\mathrm{NaCl}$ and $\mathrm{HCl}$ were chosen as an alternative for the acetate buffer, because the seal which separated the two permeate sections was poorly resistant to the acetate buffer. No evidence was found that BSA behaved differently for the two types of solutions with an equal $\mathrm{pH}$ value of 4.5 and an equal ionic strength of $0.15 \mathrm{kmol}$ $\mathrm{m}^{-3}$. All solutions were protected from bacterial growth by adding $0.5 \mathrm{~kg} / \mathrm{m}^{3} \mathrm{NaN}_{3}$ and storage at $4^{\circ} \mathrm{C}$. The water used for the experiments was filtered through a Milli-Q-system.

\subsection{Apparatus}

\section{Stirred cell}

The rejection measurements for PEG/BSA and dex$\mathrm{tran} /$ silica were carried out in a stirred batch cell ( Amicon, type $2000 \mathrm{~A}$ ) at $298 \mathrm{~K}$. The internal diameter of the cell is $14 \times 10^{-2} \mathrm{~m}$. The bar-like stirrer has a diameter of $12 \times 10^{-2} \mathrm{~m}$. Since electrochemical measurements showed that the mass transfer coefficient increases from the centre of the membrane towards the edge, similar cells were built with the possibility to collect the permeate in two separate streams, further referred to as inner and outer section [18]. The membrane area connected with the inner permeate section was $72 \times 10^{-4} \mathrm{~m}^{2}$, the area connected with the outer section was $88 \times 10^{-4} \mathrm{~m}^{2}$. The cell was pressurized with nitrogen gas and the temperature was controlled by a thermostat. The permeate was collected in a time-based fraction collector to be able to take samples from the various fractions for concentration analysis. The amount of permeate was determined gravimetrically.

The ultrafiltration experiments were performed with asymmetric YM30 membranes having a MW cut-off of $30000 \mathrm{Da}$. The membrane material is regenerated cellulose. The membrane resistance of the clean membrane was determined $1.8 \times 10^{12} \mathrm{~m}^{-1}$.

\section{Tubular module}

The rejection measurements for PEG/silica were performed in a tubular cross-flow ultrafiltration module (UF-1, Stork Friesland, The Netherlands) at $298 \mathrm{~K}$. The module was pressurized with a centrifugal pump, which also provided the circulation through the module. The system was run in continuous mode, the permeate and concentrate were both returned to the storage vessel. The length of the membrane was $1.8 \mathrm{~m}$, the internal diameter of the membrane tube is $14.4 \times 10^{-3}$ $\mathrm{m}$ and the area was $0.08 \mathrm{~m}^{2}$. In order to characterize any entrance or exit effects the permeate was collected in four separate streams (positions $1-4,1=$ entrance, length per position $=0.45 \mathrm{~m}$ ). The ultrafiltration experiments were performed with WFBX 0121 membranes (Stork Friesland) having a molecular weight cut-off of $10000 \mathrm{Da}$ for PEG and $50000 \mathrm{Da}$ for dextran. The membrane material is hydrophilic polysulfone, applied on a composite polyester non-woven carrier. The membrane resistance of the clean membrane was determined $4.5 \times 10^{12} \mathrm{~m}^{-1}$.

The reason to perform part of the rejection measurements in the tubular module was the expectation that the mass transfer in this tubular module would be better defined than in the stirred cell. Moreover, the tubular module is representative for commercial scale modules, in which a number of those pipes are gathered. Given the costs of dextran and BSA the measurements with these components could not be carried out in the tubular module with its ten times larger liquid hold-up.

\subsection{Method}

\section{PEG/silica (Aerosil)}

To characterize the influence of a deposit layer on the PEG rejection the following procedure has been used:

1. Determination of the PEG rejection on the clean membrane as a function of the flux by filtering a 10 $\mathrm{kg} / \mathrm{m}^{3}$ PEG solution at various pressures.

2. Formation of a silica deposit layer on the membrane by filtering a $30 \mathrm{~kg} / \mathrm{m}^{3}$ Aerosil 200 suspension at a constant pressure.

3. Determination of the PEG rejection in the presence of the previously formed silica deposit layer as a function of the flux by filtering a PEG/water solution at various pressures and two types of PEG.

Since Aerosil tends to agglomerate in water the following procedure was used to prepare the suspension. The Aerosil was suspended in water using a TURRAX mixer. Afterwards the suspension was given a repeated ultrasonic treatment until the viscosity of the silica suspension did not change anymore.

The flux during Aerosil filtration was followed as a function of time. The filtration was stopped when the stationary flux was reached and the deposit layer for- 
mation was completed. After the silica filtration the module was disconnected and the suspension was allowed to flow out of the system. After reconnection the system was carefully filled with water. The first part of the water which had run through the module was not returned to the feed vessel in order to clean the system from "free" silica which was not incorporated in the deposit layer.

A pure water flux was measured to check the condition of the deposit layer. Subsequently, the system was filled with a PEG/water solution, the system was pressurized and the flux and rejection were measured as a function of time until a steady-state situation was reached. The PEG rejection measurements were repeated on the same deposit layer for various pressures, circulation velocities and two types of PEG of different molecular weight.

After the rejection measurements were performed, the tubular membrane was removed from the module and cut in twelve equal pieces. From each part several samples of the deposit layer were taken to determine the thickness of the deposit layer and the deposit concentration along the entire length of the membrane.

\section{Dextran/silica (Ludox)}

In contrast with the experiments performed with Aerosil and PEG, the deposit layer formation occurred during the simultaneous filtration of Ludox and dextran at a $\mathrm{pH}$ value of 6.1 and three different pressures (50, 100 and $200 \mathrm{kPa}$ ). The concentrations of Ludox and dextran were $50 \mathrm{~kg} / \mathrm{m}^{3}$ and $10 \mathrm{~kg} / \mathrm{m}^{3}$, respectively. The $\mathrm{pH}$ was adjusted by adding $\mathrm{HNO}_{3}$. In the case of Ludox it was not possible to separate the formation of the deposit layer and the dextran rejection measurements, because the Ludox layer was too weak for the handling involved in such a kind of experiment. For the same reason no deposit concentration or deposit thickness could be measured after the experiment. The deposit concentration of Ludox was determined in separate centrifugation experiments.

\section{PEG/BSA}

Several phenomena can occur during protein filtration: adsorption on the membrane surface or inside pore, deposition on the membrane surface, compression of the deposition layer, and osmotic pressure of the protein. To characterize the influence of these phe- nomena on the PEG rejection the following procedure was used:

1. The pure water flux and the saline flux were measured as a function of pressure.

2. The PEG rejection on the clean membrane was determined as a function of the flux by varying the pressure.

3. The membrane was soaked in a BSA solution of the same concentration and $\mathrm{pH}$ as the bulk concentration which was used in the filtration experiments for approximately $24 \mathrm{~h}$ at $4^{\circ} \mathrm{C}$. After the membrane was mounted in the cell, the resistance was evaluated to check on possible adsorption by measuring the saline flux at various pressures. Also the PEG rejection was again determined by filtering PEG in the saline solution.

4. A PEG/BSA solution was filtered at a range of pressures and a constant bulk concentration on a clean membrane. The effect of possible adsorption and deposition was checked after the experiment by the saline flux and the PEG rejection in a saline solution.

The procedure described above was performed on one single membrane for each $\mathrm{pH}$ value. The resistances of the clean membranes were within $5 \%$ with an average value of $1.8 \times 10^{12} \mathrm{~m}^{-1}$.

\subsection{Concentration analysis}

The PEG or dextran concentrations in the samples were determined by HPLC (High Performance Liquid Chromatography). In the case of the PEG/Aerosil/ water systems the permeate only contained PEG. A small Bio-SIL SEC 250 guard column (Biorad) was used since no separation of components was necessary. Deionized water filtered through the Milli-Q-system was used as eluent. The concentrations were determined by a refractive index detector (LKB, 2142). A standard solution with a known quantity PEG was alternately analyzed with the samples. The samples were measured in duplicate and the deviation between both duplicate measurements was 1-3\%.

If the samples contained salt, as was the case for the dextran/Ludox/water and the PEG/BSA/water systems, they were analyzed using a Zorbax GF250 column. This column was able to separate dextran and salt (Ludox was totally rejected by the membrane). 
In the case of PEG/BSA a saline solution of $\mathrm{pH}=7.4$ of the same composition as described under Model components was chosen as eluent, because BSA would not elute from the column if water was used. The UVanalysis of the permeate concentration of BSA (at 280 $\mathrm{nm}$ ) showed that the membranes were fully retentive for BSA. The $\mathrm{pH}$ of the permeate and retentate remained within $0.05 \mathrm{pH}$-units throughout the experiment.

\section{Results}

\subsection{Silica deposits}

PEG rejection in the presence of an Aerosil deposit layer

The PEG rejection on the clean membrane was measured by filtering a $10 \mathrm{~kg} / \mathrm{m}^{3} \mathrm{PEG}$ solution in the tubular module. The observed rejection showed a characteristic maximum in the rejection as a result of the decrease in rejection at higher fluxes due to concentration polarization [19]. The permeate was collected in four separate streams (see Method): the rejections for positions 2-4 were similar, however higher rejections were measured at the first position in the flux region where concentration polarization becomes important. This indicates that the mass transfer at the first position is higher due to entrance effects. A characteristic example of the behaviour of the PEG rejection as a function of the flux on the clean membrane is shown in Fig. 2 (averaged for positions 2-4). The PEG rejection in the presence of a deposit layer will be discussed shortly after.

Subsequently, an Aerosil suspension was filtered at $200 \mathrm{kPa}$ and at constant circulation flow rate until steady-state was reached and the deposit layer formation was completed. The deposit concentration and the final deposit thickness were determined experimentally as a function of the distance from the inlet of the tubular module (see Method). The average deposit concentration over the entire length of the membrane was equal to $309 \mathrm{~kg} / \mathrm{m}^{3}$ with a standard deviation of $3.4 \mathrm{~kg} / \mathrm{m}^{3}$. The deposit thickness was found to be $1.24 \mathrm{~mm}$ with a standard deviation of $0.07 \mathrm{~mm}$. However, there was hardly any deposit layer over the first 2 to $3 \mathrm{~cm}$ of the membrane. This also indicates the existence of entrance effects, which alter the mass transfer in the first few centimetres of the tubular membrane.

After the Aerosil layer was brought onto the membrane surface a PEG solution was filtered through the membrane + deposit layer. In Table 1 the steadystate flux and the observed rejection in the presence of a deposit layer are presented for PEG3400 and PEG6000 at various pressures. Moreover, the observed rejection on a clean membrane is given at the same flux, $v_{\mathrm{ss}}$, as the steady-state flux in the presence of the deposit layer. The pressures in Table 1 correspond to the rejec-

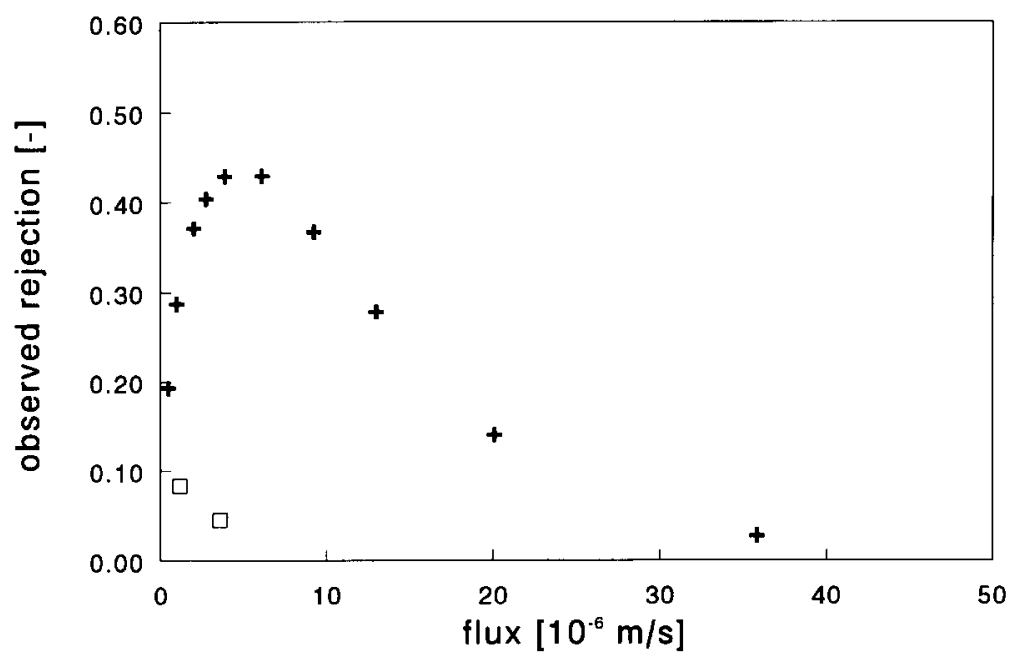

Fig. 2. PEG6000 rejection in the presence $(\square)$ and absence $(+)$ of an Aerosil deposit layer. $u_{\text {circ }}=1.04 \mathrm{~m} / \mathrm{s}$ without deposit and $1.51 \mathrm{~m} / \mathrm{s}$ with deposit. $C_{\mathrm{PEG}}=10 \mathrm{~kg} / \mathrm{m}^{3}$. 
Table 1

Experimental flux and rejection during the filtration of PEG in the presence and absence of a deposit layer

\begin{tabular}{|c|c|c|c|c|c|}
\hline \multicolumn{4}{|c|}{ Membrane with deposit layer } & \multicolumn{2}{|l|}{ Clean membrane } \\
\hline Component & $\begin{array}{l}\text { Pressure } \\
(\mathrm{kPa})\end{array}$ & $\begin{array}{l}v_{s s} \\
\left(10^{-6} \mathrm{~m} / \mathrm{s}\right)\end{array}$ & $\begin{array}{l}R_{\mathrm{obs}}^{\text {deposit }}(-) \\
u_{\mathrm{circ}}=1.51 \mathrm{~m} / \mathrm{s}\end{array}$ & $\begin{array}{l}R_{\mathrm{obs}}^{\mathrm{a}}(-) \\
u_{\mathrm{circ}}=1.04 \mathrm{~m} / \mathrm{s}\end{array}$ & $\begin{array}{l}R_{\mathrm{obs}}^{\mathrm{a}}(-) \\
u_{\mathrm{circ}}=1.95 \mathrm{~m} / \mathrm{s}\end{array}$ \\
\hline PEG3400 & 36 & 1.00 & 0.021 & 0.07 & \\
\hline PEG3400 & 55 & 1.30 & 0.062 & 0.06 & \\
\hline PEG3400 & 107 & 4.00 & 0.012 & 0.16 & 0.19 \\
\hline PEG6000 & 36 & 1.18 & 0.083 & 0.30 & \\
\hline PEG6000 & 103 & 3.60 & 0.045 & 0.41 & 0.49 \\
\hline
\end{tabular}

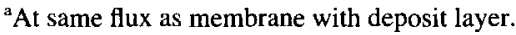

tion measurements in the presence of a deposit layer. It is very important to compare the observed rejection at the same flux instead of at the same pressure, because the concentration profile in the polarization layer is determined by the flux divided by the mass transfer coefficient (eqn. 3 ) and the actual rejection is a function of the flux.

The PEG rejection measurements with and without a deposit layer were performed at the same circulation rate. Due to the presence of a deposition layer the hydraulic diameter and circulation velocity were different in the first case, which implies different mass transfer coefficients in both cases. Since the mass transfer coefficient is only minor influenced by the hydraulic diameter $\left(d_{\mathrm{h}}^{-0.2}\right)$, it is assumed that the mass transfer coefficients are equal at equal circulation velocities. After all the experiments were finished the gel layer thickness was measured (see method) and the circulation velocity was calculated to be $1.51 \mathrm{~m} / \mathrm{s}$. The PEG rejections on the clean membrane are measured for a circulation velocity of $1.04 \mathrm{~m} / \mathrm{s}$ and $1.95 \mathrm{~m} / \mathrm{s}$ at the highest permeate flux. The PEG rejections with and without deposit layer should be compared at the same circulation velocity. The value for the observed PEG rejection at a circulation velocity of $1.51 \mathrm{~m} / \mathrm{s}$ without a deposit layer will be higher than the value for 1.04 $\mathrm{m} / \mathrm{s}$, but lower than the value for $1.95 \mathrm{~m} / \mathrm{s}$.

As an example the PEG6000 rejection both in the presence and absence of the deposit layer is shown in Fig. 2. In both Table 1 and Fig. 2 the presented rejections only hold for position 2,3 and 4 of the membrane module. The behaviour of the rejection at position 1 will be discussed later.
From Table 1 and Fig. 2 it can be concluded that the observed rejection in the presence of a deposit layer is almost equal to zero. Especially for both experiments with PEG6000 and the experiment with PEG3400 at a pressure of $107 \mathrm{kPa}$ it can be clearly seen that the observed rejection in the presence of a deposit layer at a circulation velocity of $1.51 \mathrm{~m} / \mathrm{s}$ is considerably lower than the rejection on a clean membrane at a circulation velocity of $1.04 \mathrm{~m} / \mathrm{s}$. Because the rejection on a clean membrane for a circulation velocity of $1.51 \mathrm{~m} / \mathrm{s}$ would be higher than at $1.04 \mathrm{~m} / \mathrm{s}$, the actual drop in rejection at equal circulation velocities would even be larger. This means that due to the presence of a silica deposit layer on the membrane surface the separation behaviour is completely changed. A normally partly rejected PEG solution almost totally permeates through the membrane if a deposit layer is present.

The fact that the PEG rejection drops to almost zero in the presence of a deposit layer can be understood if the following conditions are fulfilled:

1. The Aerosil layer shows hardly any exclusion for PEG3400 and PEG6000.

2. The thick Aerosil layer causes a strong decrease in back-diffusion of PEG to the bulk solution.

If the deposit layer is sufficiently thick, the steadystate permeate concentration will not be determined by the rejection of the membrane, but will instead be governed by the extent of solute exclusion by the deposit layer. If the deposit layer is sufficiently open that PEG exclusion is negligible, the steady-state permeate concentration is determined by the extent to which the solute diffuses back to the bulk solution through the deposit layer. In the presence of a deposit layer the 
back-diffusion will diminish and the concentration at the membrane surface and therefore also the permeate concentration can reach very high values. For a thick deposit layer the diffusive flux will approach zero near the bulk-deposit layer interface. In that case the permeate concentration will be equal to the bulk concentration, because for negligible back-diffusion the convective transport to the membrane $v \cdot C_{\mathrm{b}}$ can be considered equal to the solute flux in the permeate $v \cdot C_{\mathrm{p}}$. The concentration at the membrane surface has then reached a value of $C_{\mathrm{b}} /\left(1-R_{\mathrm{a}}\right)$. If the bulk and permeate concentration have the same value, the observed rejection $R_{\mathrm{obs}}$ is equal to zero. The observed rejection is only zero, if the deposit layer does not show any exclusion for the solute and the back-diffusion is negligible. In general, the back-diffusion can be neglected if the $P e$-number in the deposit layer, $K_{\mathrm{c}} v \delta_{\mathrm{dep}} /\left(\epsilon_{\mathrm{dep}} K_{\mathrm{d}} D / \tau\right)$, is larger than about 5 (see Fig. 1). For the Aerosil deposit layer with a thickness of $1.24 \mathrm{~mm}, v=4 \mu \mathrm{m} \mathrm{s}^{-1}, K_{\mathrm{c}}=K_{\mathrm{d}}=1$ and PEG diffusivities of $1.1-1.4 \times 10^{-10} \mathrm{~m}^{2} \mathrm{~s}^{-1}$ and a porosity of 0.86 the $P e_{\text {dep }}$ is about 50 .

According to this figure the rejection of PEG should be zero. The fact that the measured rejections (Table 1) were slightly higher than zero could be ascribed to some extent of exclusion by the deposit layer.

In Fig. 3 the experimentally measured permeate concentration of PEG3400 is depicted as a function of time for the four membrane positions, if an Aerosil layer of $1.24 \mathrm{~mm}$ thickness is present on the membrane. The permeate concentrations at positions 2, 3 and 4 clearly show the increase in concentration with time starting from zero to the same steady-state value. The permeate concentration at position 1 is higher in the beginning but reaches a lower steady-state value. This can be explained by the absence of a deposit layer on the first few centimetres near the membrane inlet. Due to the absence of the deposit layer, the water hold-up is only that of the membrane itself and its support layer and the PEG solution has to displace less water compared to the other positions. Therefore the permeate concentration starts to increase much earlier. Part of the membrane in position 1 keeps a rejection for PEG, because it is not covered by a deposit layer. Thus the end value of the permeate concentration stays below that of positions 2, 3 and 4 . The same deviation has also been observed for the other experiments.
The unsteady-state rejection has been modelled with a time-dependent transport equation [20]. Calculations have shown that the experimental time to reach steadystate is much longer than theoretically expected. The adsorption of PEG on the silica particles was found to delay the steady-state and this effect should be incorporated in the model. The PEG adsorption on the silica layer had no effect on the permeability of the deposit layer according to pure water flux measurements before and after the PEG rejection measurements.

Dextran rejection during the simultaneous filtration of Ludox and dextran

The drop in PEG rejection in the presence of the Aerosil layer is caused by its open structure compared to that of the membrane. To study the rejection by a more compact deposit layer, another type of silica (Ludox) was used, still in suspension at $500 \mathrm{~kg} / \mathrm{m}^{3}$, which is higher than the deposit concentration for Aerosil. Since Ludox formed a mechanically weak deposit layer, it was not possible to replace the Ludox suspension by a PEG solution without destruction of the deposit layer. Therefore it was necessary to filter PEG and Ludox simultaneously. Adsorption of PEG on the Ludox particles caused a considerable drop in the bulk concentration of PEG and the PEG concentration could not be determined very accurately in the presence of Ludox. Therefore dextranT40 was used instead of PEG, because it hardly adsorbed on the Ludox particles.

The dextran rejection is presented in Fig. 4 with and without Ludox present in the solution. The observed dextran rejection without Ludox is equal to 0.90 at the lowest fluxes and decreases with increasing fluxes due to concentration polarization. The decrease is stronger for the inner permeate section because the mass transfer coefficient is lower and therefore the degree of polarization is stronger.

The flux during the filtration of dextran/Ludox decreases very rapidly and within a few minutes steadystate is reached. After filtration a thin, weak deposit layer is visible on the membrane surface, but no sample could be taken to determine the deposit concentration. Separately performed centrifugation experiments have shown that the deposit concentration of thin weak Ludox layers is about $700 \mathrm{~kg} / \mathrm{m}^{3}$.

The influence of the presence of a Ludox deposit layer is found by comparing the dextran rejection with and without Ludox at the same flux (see also Table 2). 


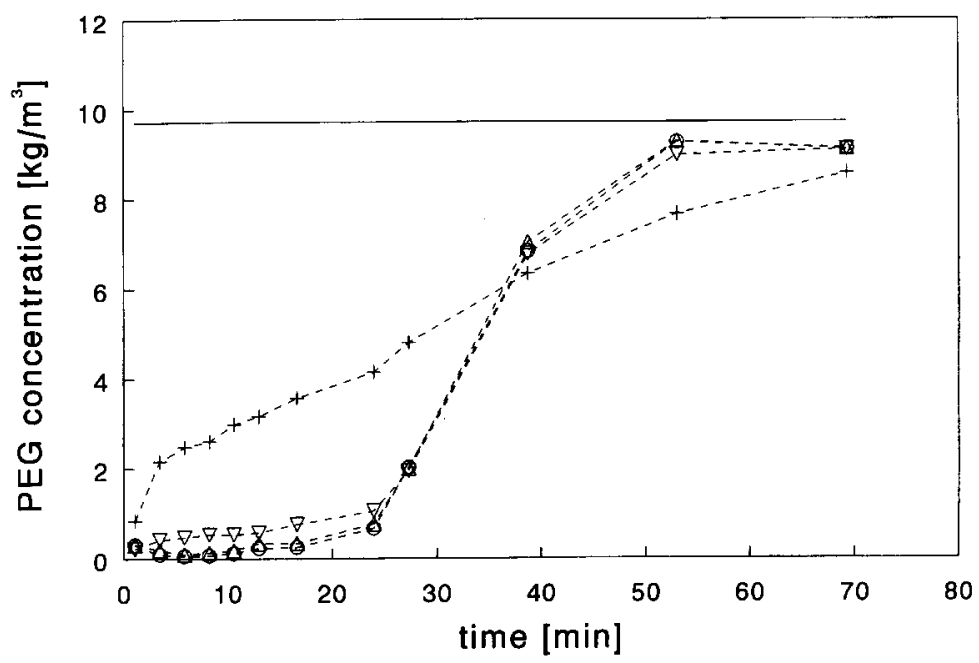

Fig. 3. Permeate concentration of PEG3400 in the presence of an Aerosil gel layer as a function of time after switching from water to PEG solution for four membrane positions. $u_{\mathrm{circ}}=1.51 \mathrm{~m} / \mathrm{s}, \Delta P=55 \mathrm{kPa} . C_{\mathrm{p}, \mathrm{PEG}}$ : position $1(+)$, position $2(\triangle)$, position $3(\mathrm{O})$, position $4(\nabla)$; $C_{\mathrm{b}, \text { PEG }}:(-)$.

It can be seen that for both the inner and outer permeate section the dextran rejection drops in the presence of Ludox. The dextran rejection decreases with increasing pressure. This is the result of the increase in deposit layer thickness on the membrane surface as a function of pressure, which diminishes the back-diffusion in the Ludox deposit layer ( see discussion for PEG and Aerosil). In the inner section at 100 and $200 \mathrm{kPa}$ the dextran rejection even drops to zero, which is much lower than the values of 0.77 and 0.79 for the clean membrane.
The fact that the rejection drops to zero indicates that dextranT40 is not excluded by the Ludox deposit layer. The observed rejections with and without a deposit layer were used to calculate values of $P e_{\text {dep }}$ by means of Eq. (4). From these values the thickness of the deposit layer (see Table 2) could be obtained using $\varepsilon_{\text {dep }}=0.70$ and $D=6 \times 10^{11} \mathrm{~m}^{2} \mathrm{~s}^{-1}$ and $K_{\mathrm{c}}=K_{\mathrm{d}}=1$ and assuming that the tortuosity is only slightly larger than 1. A check/confirmation of the calculated values for the deposit layer thickness from hydraulic resistances

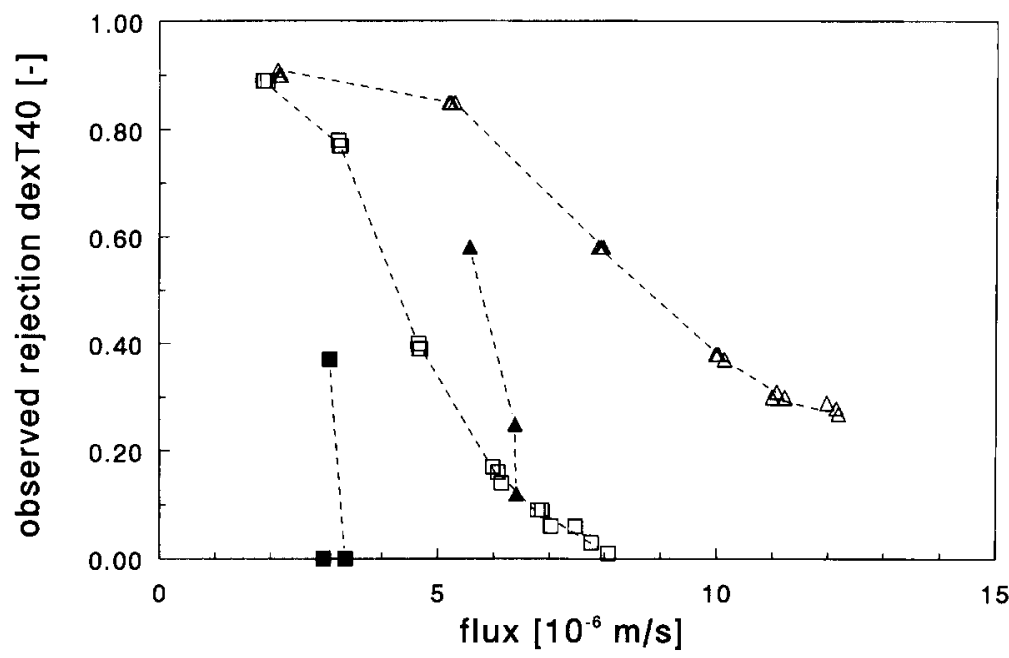

Fig. 4. DextranT40 rejection in the presence and absence of Ludox. $90 \mathrm{rpm}, C_{\mathrm{dex}}=10 \mathrm{~kg} / \mathrm{m}^{3}$. Open symbols: only dextran; closed symbols: dextran + Ludox, $C_{\text {Ludox }}=50 \mathrm{~kg} \mathrm{~m}^{-3}$. Inner section $(\square)$, outer section $(\Delta)$. 
Table 2

Experimental flux and rejection during the filtration of dextranT40 in the presence and absence of Ludox.

\begin{tabular}{|c|c|c|c|c|c|c|c|c|}
\hline \multicolumn{7}{|c|}{ DextranT40/Ludox } & \multicolumn{2}{|c|}{$\begin{array}{l}\text { Clean } \\
\text { membrane }\end{array}$} \\
\hline $\begin{array}{l}\text { Pressure } \\
(\mathbf{k P a})\end{array}$ & $\begin{array}{l}v_{\mathrm{ss}} \\
\text { inner } \\
(\mu \mathrm{m} / \\
\mathrm{s})\end{array}$ & $\begin{array}{l}v_{\mathrm{ss}} \\
\text { outer } \\
(\mu \mathrm{m} / \\
\mathrm{s})\end{array}$ & $\begin{array}{l}R_{\mathrm{obs}}^{\mathrm{dep}} \\
\text { inner } \\
(-)\end{array}$ & $\begin{array}{l}R_{\mathrm{obs}}^{\mathrm{dep}} \\
\text { outer } \\
(-)\end{array}$ & $\begin{array}{l}\delta_{\text {dep }} \\
\text { inner } \\
(\mu \mathrm{m})\end{array}$ & $\begin{array}{l}\delta_{\text {dep }} \\
\text { outer } \\
(\mu \mathrm{m})\end{array}$ & $\begin{array}{l}R_{\mathrm{bbs}}^{\mathrm{a}} \\
\text { inner } \\
(-)\end{array}$ & $\begin{array}{l}R_{\mathrm{obs}}^{\mathrm{a}} \\
\text { outer } \\
(-)\end{array}$ \\
\hline 50 & 3.06 & 5.57 & 0.37 & 0.58 & 25 & 10 & 0.78 & 0.83 \\
\hline 100 & 3.35 & 6.38 & 0.00 & 0.25 & $80^{b}$ & 15 & 0.77 & 0.70 \\
\hline 200 & 2.96 & 6.41 & 0.00 & 0.12 & $90^{\mathrm{b}}$ & 25 & 0.79 & 0.69 \\
\hline
\end{tabular}

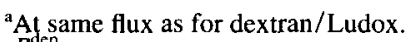

$\mathrm{b} R_{\mathrm{obs}}^{\mathrm{dep}}$ taken as 0.005 , else the thickness would be infinite.

proved impossible due to the inaccuracy in the value of the calculated osmotic pressure. Table 2 shows that a deposit layer with relatively small thickness of 10 $25 \mu \mathrm{m}$ may considerably decrease the observed rejection.

We have also performed the same type of experiments with the higher molecular weight dextranT250. Due to the low diffusion coefficient of dextranT250 the concentration polarization of dextranT250 is considerably higher than for dextranT40. As a result the osmotic pressure is so high that Ludox was not able to form a deposit layer anymore or only a very thin layer, at the Ludox bulk concentration of $50 \mathrm{~kg} / \mathrm{m}^{3}$ and the stirrer speed of $90 \mathrm{rpm}$. In that case no significant change in the observed rejection of dextranT 250 could be determined in the presence of Ludox.

The fact that no exclusion seems to occur at the retentate/deposit interface for dextranT40 was not foreseen, and is quite surprising in view of the particle size of Ludox: $12 \mathrm{~nm}$. This size is not much larger than that of the ovalbumin molecules (average molecular weight 45000 ) used by Nakao et al. [1] where the deposit layer showed rejection even for raffinose and glucose. Based on the measured rejections Nakao et al. calculated a pore diameter between 0.74 and $0.77 \mathrm{~nm}$ for the ovalbumin layer. Since the diameter of the dextran molecule is 6 (based on molecular weight) to 10 (based on diffusivity) times as large as the glucose molecule some degree of exclusion by the Ludox layer was expected, if the porous structure was similar to the ovalbumin layer.

A possible explanation may be found in the relatively high porosity of the deposit layers: 0.87 for the Aerosil layer and 0.70 for the Ludox. These values are calculated from the measured deposit concentrations and a particle density of $2250 \mathrm{~kg} / \mathrm{m}^{3}$. The porosities are high compared to those of a random packed bed: 0.4 . For the Aerosil layer it is very likely that it is composed of agglomerates of primary particles since the Aerosil suspension was proven to contain already mainly agglomerates [18]. This could explain the fact that the observed PEG rejection is almost zero in the presence of the Aerosil layer. Although the starting Ludox suspension consisted of primary particles ( $\mathrm{pH}$-stabilized, the viscosity was in accordance with Einstein relation ) agglomerates may have been formed during deposition due to the adjustment of the $\mathrm{pH}$ value below 7. According to Iler [21] three-dimensional gel networks can be formed in that $\mathrm{pH}$ range. Both the porosity and the pore size of a layer composed of irregularly shaped (often string-like) agglomerates will be higher than that of a deposit of primary particles.

\section{Summary of the results for silica deposits}

In the presence of an Aerosil deposit layer of 1.24 $\mathrm{mm}$ thickness and a porosity of 0.86 , the observed rejection for PEG3400 and PEG6000 drops to almost zero. This phenomenon can be explained by assuming that the deposit layer present does not show any exclusion for PEG. Due to the thickness of the deposit layer, the diffusion back to the bulk solution is strongly decreased, which results in a total permeation of the bulk solution through the membrane, when the $P e$ number in the deposit layer is larger than about 5 .

The same type of effects has been found during the simultaneous filtration of dextranT40 and Ludox. It is shown that the increase of the deposit layer thickness causes a decrease in rejection ( to even zero) due to the diminishing back-diffusion.

\subsection{BSA deposits}

\section{Influence of BSA adsorption on the PEG rejection}

The adsorption of BSA on the membrane was performed with a $10 \mathrm{~kg} / \mathrm{m}^{3} \mathrm{BSA}$ solution of the same $\mathrm{pH}$ as the solutions used for the subsequent measurements. After the membrane was soaked in the BSA solution 
the resistance was measured with a saline solution of the same $\mathrm{pH}$. For both $\mathrm{pH}=7.4$ and $\mathrm{pH}=4.5$ the increase in resistance is $2-3 \%$. There is no significant difference in resistance between both $\mathrm{pH}$ values. Probably, the slight dependence of the adsorption on the $\mathrm{pH}$ above the isoelectric point [22] cannot be detected at such a low amount of adsorption. The low adsorption corresponds with the measurements of Sheldon [23], who has determined the combined effect of adsorption and deposition on YM10 membranes. She found an increase in resistance of $4.5 \%$ at $\mathrm{pH}=7.0$. Considerably stronger adsorption has been reported on polyethersulfone [7] and polysulfone membranes [22].

To determine whether the influence of the BSA adsorption on the PEG rejection is more pronounced than on the membrane resistance (as found by Ingham and Busby $[8,9]$ ), PEG in saline solutions was filtered through the adsorbed membranes. For both $\mathrm{pH}$ values no significant changes in PEG rejection were found for the adsorbed regenerated cellulose membrane. Also the flux during the PEG filtration was hardly effected by the adsorption.

\section{Influence of BSA deposition on the PEG rejection with- out BSA in solution}

After the filtration of a $10 \mathrm{~kg} / \mathrm{m}^{3}$ solution of both BSA and PEG at $200 \mathrm{kPa}$ the membrane was checked on possible protein deposition and its influence on the PEG rejection. According to saline fluxes measured directly after the BSA filtration experiment the membrane resistance had increased in both permeate sections for $\mathrm{pH}=7.4: 2-5 \%$ for the inner section and $3-6 \%$ for the outer section. The membrane resistance depended on the pressure and increased with increasing pressure from 25 to $200 \mathrm{kPa}$. The rise in membrane resistance at $\mathrm{pH}=4.5$ also increased with pressure and was equal to $3-11 \%$ for the inner permeate section and $2-7 \%$ for the outer section. The higher resistance in the inner section is due to the lower mass transfer coefficient, which encourages deposit formation.

From the membrane resistance measurements it can be concluded that at both $\mathrm{pH}$ values protein was deposited on the membrane. The dependence of the membrane resistance on the pressure indicated that the deposition layer was compressible. The occurrence of compressible protein layers was mentioned before in the literature $[1,7,24]$. At the highest pressure the deposition at $\mathrm{pH}=4.5$ caused a stronger decrease in fiux than at $\mathrm{pH}=7.4$. This is in accordance with the measurements of Opong [25], who showed that the saline flux through a BSA deposit formed at $\mathrm{pH}=7.4$ and a ionic strength of $0.15 \mathrm{kmol} \mathrm{m}^{-3}$ is considerably higher than the flux through a deposit formed at $\mathrm{pH}=4.5$ and the same ionic strength. These measurements were performed on a polyethersulfone membrane. Suki et al. [12] have measured the amount of BSA deposited on a YM30 membrane from an aqueous solution and reported a higher amount of deposition at $\mathrm{pH}=4.5$ compared to at $\mathrm{pH}=7.4$.

To determine the influence of the deposition on the PEG rejection a PEG solution of the same $\mathrm{pH}$ was filtered through the BSA deposit. The PEG rejection as a function of the flux is shown in Fig. 5a and the fluxes with the corresponding pressures during the PEG filtration in Fig. 5b are depicted for $\mathrm{pH}=7.4$. Fig. $6 \mathrm{a}$ and Fig. $6 \mathrm{~b}$ show the results for $\mathrm{pH}=4.5$. At low fluxes (low pressures) no influence of the BSA deposit was found for both $\mathrm{pH}$ values. At high fluxes still no significant change in PEG rejection was measured for $\mathrm{pH}=7.4$, but a slight increase in observed rejection could be determined for $\mathrm{pH}=4.5$. The flux as a function of pressure provides a clearer evidence of the occurrence of an increase in rejection. At 100 and $200 \mathrm{kPa}$ a strong decrease in flux is measured for $\mathrm{pH}=4.5 \mathrm{com}$ pared to the flux from a PEG solution without the presence of a BSA deposit. This decrease is stronger than would be expected from the change in membrane resistance due to the presence of the deposit as discussed earlier. The additional lowering of the flux is due to an increase in osmotic pressure as a result of the higher rejection of PEG. The higher rejection of PEG causes a rise in the concentration at the membrane surface and therefore an increase in the osmotic pressure. Calculations with the osmotic pressure model confirm that the fluxes are in the range of what would be expected on basis of the observed rejections. The flux measurements support the augmented PEG rejection at the highest pressures for $\mathrm{pH}=4.5$. Although no significant change in PEG rejection was found for $\mathrm{pH}=7.4$ it seems reasonable to conclude from the flux measurements that at $200 \mathrm{kPa}$ the deposit caused a slight increase in the PEG rejection.

The fact that the difference in PEG rejection with and without a BSA deposit depends on the pressure suggests that the deposit layer is compressed at higher pressures. This compressive behaviour is the main rea- 

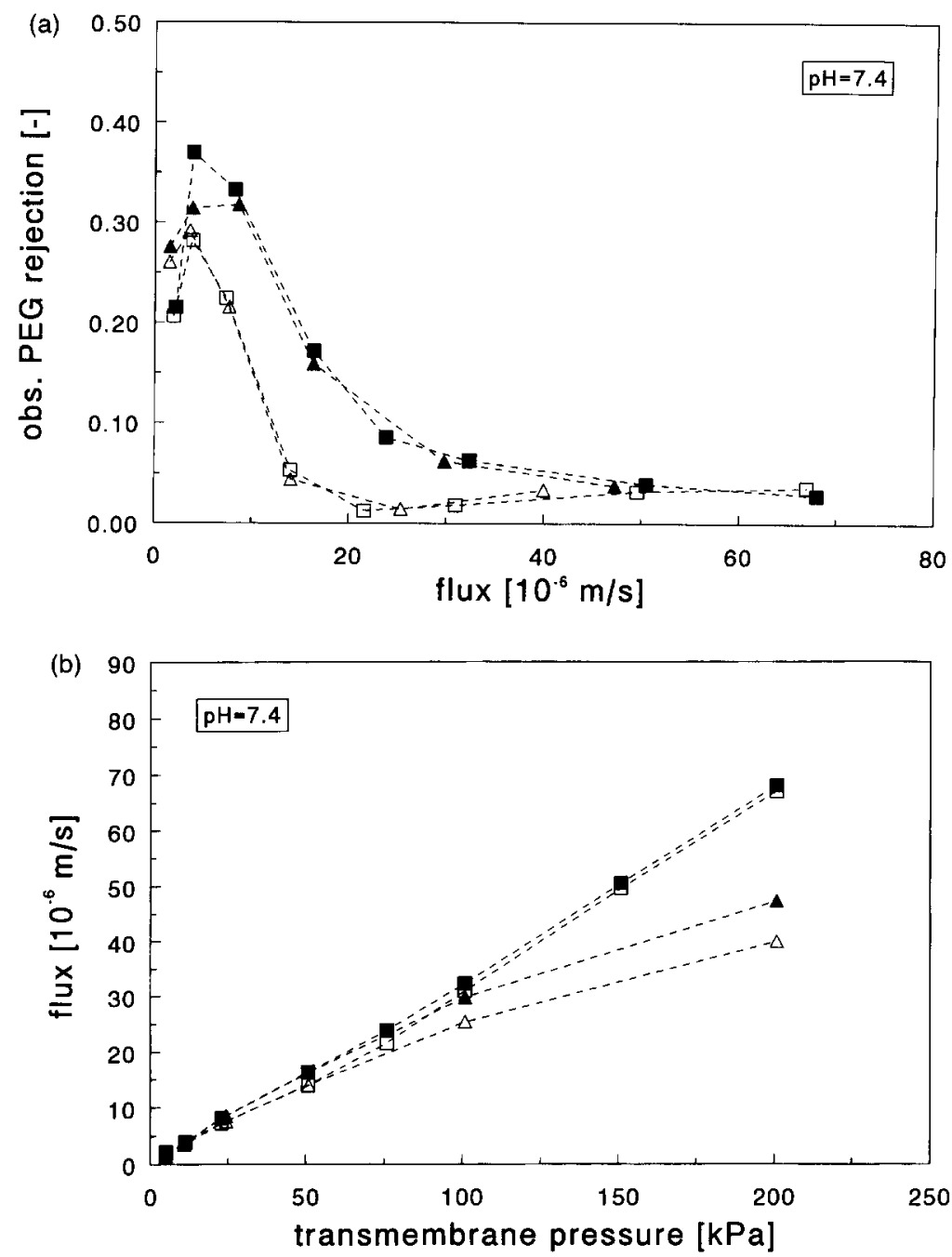

Fig. 5. (a) Observed PEG3400 rejection as a function of the flux on a clean membrane ( $\square$ ) and after the filtration of a $10 \mathrm{~kg} \mathrm{~m}{ }^{-3} \mathrm{BSA}+10 \mathrm{~kg}$ $\mathrm{m}^{-3}$ PEG solution $(\triangle) . n=90 \mathrm{rpm}, \mathrm{pH}=7.4$. Open symbols, inner section; closed symbols, outer section. (b) Flux as a function of the transmembrane pressure for the same experiments.

son for assumption that we deal with a deposit layer rather than with pore blockage [26]. This is in accordance with the results from the membrane resistance measurements with the saline solutions.

We will now discuss the influence of the $\mathrm{pH}$ on the rejection and make a comparison with literature data. Comparing the influence of the deposit for the two $\mathrm{pH}$ values it is clear that the deposit at $\mathrm{pH}=4.5$ has a stronger effect on the flux and the PEG rejection. The flux is determined by both the compactness, influencing $\phi_{\text {dep }}$, and the thickness of the deposit layer, influencing $P e_{\text {dep }}$. The distinctly higher $\mathrm{PEG}$ rejection at $\mathrm{pH}=4.5$ compared to that at $\mathrm{pH}=7.4$ points in the direction of a more compact BSA deposit at $\mathrm{pH}=4.5$ than $\mathrm{pH}=7.4$. Both Opong and Zydney [7] - who measured the hydraulic resistances of BSA deposits - and Mochizuki and Zydney [5] - who measured dextran rejections of BSA deposits - concluded that the compactness of the BSA deposit at $\mathrm{pH}=4.5$ is lower than at $\mathrm{pH}=7.4$. This behaviour is exactly the opposite of what would be expected from our rejection measurements. However, recent measurements in the research group of Zydney [27] have shown that transient effects occur if solutions of different $\mathrm{pH}$ values are filtered through the BSA 

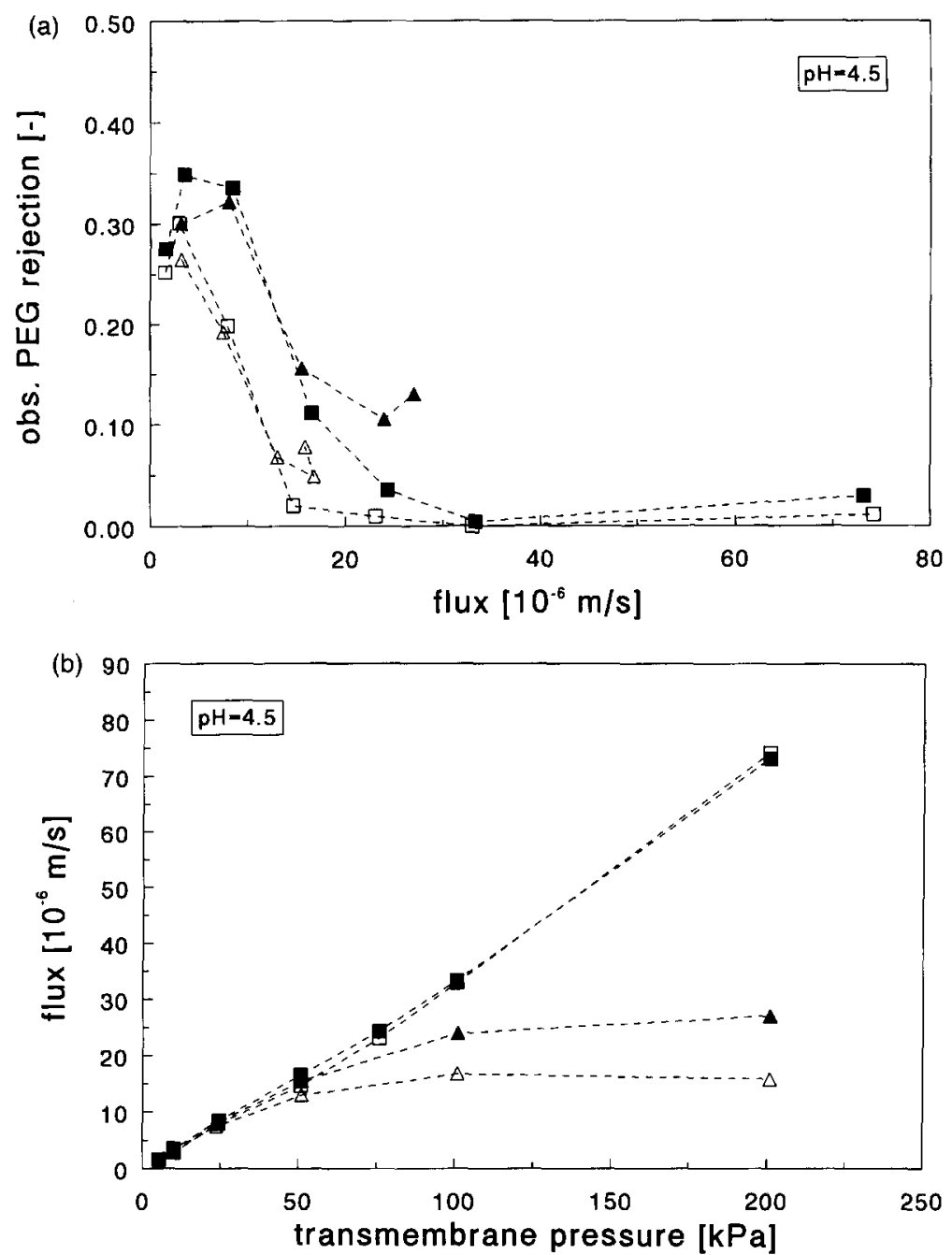

Fig. 6. (a) Observed PEG3400 rejection as a function of the flux on a clean membrane ( $\square$ ) and after the filtration of a $10 \mathrm{~kg} \mathrm{~m}{ }^{-3} \mathrm{BSA}+10 \mathrm{~kg}$ $\mathrm{m}^{-3}$ PEG solution $(\triangle) . n=90 \mathrm{rpm}, \mathrm{pH}=4.5$. Open symbols, inner section; closed symbols, outer section. (b) Flux as a function of the transmembrane pressure for the same experiments.

layer which has been deposited at $\mathrm{pH}=7.0$. When a solution of $\mathrm{pH}=4.7$ is filtered through the deposit the permeability shows a quick rise and seems to reach steady-state in a short time. However, measurements over a much longer period $(12 \mathrm{~h})$ showed that eventually the permeability will decrease again and at steady-state a lower permeability is reached compared to the permeability at $\mathbf{p H}=7.4$. The slow transient behaviour is likely to be the result of the slow reorientation of the BSA molecules trapped in the deposit compared to the rapid change of conformation of BSA molecules in bulk solution. The permeability measure- ments of Opong and the sieving measurements of Mochizuki were performed after filtering a solution of a certain $\mathrm{pH}$ value for less than one hour, when steadystate had not yet been reached. Since our rejection measurements have been carried out for the same $\mathrm{pH}$ values at which the deposits were actually formed, no transient behaviour due to $\mathrm{pH}$ changes was involved. Therefore we measured a more compact layer at $\mathrm{pH}=4.5$ than at $\mathrm{pH}=7.4$ in accordance with the steady-state values found later by Zydney. At the isoelectric point ( $\mathrm{pH}=4.7$ ) the BSA molecules have no net charge and are capable of forming more closely 
packed layers than at higher and lower $\mathrm{pH}$ values due to the absence of electrostatic repulsion.

Suki et al. [12] derived a specific hydraulic resistance for BSA deposits as a function of $\mathrm{pH}$ from unstirred filtration measurements and indeed found the highest resistance at the isoelectric point, which is in accordance with our rejection measurements. However, the specific resistances should be treated with some caution since they have been derived from the filtration data without accounting for the osmotic pressure at the various $\mathrm{pH}$ values. Since the osmotic pressure of BSA is the lowest at the isoelectric point, the specific resistance is likely to be overestimated by a greater extent at the low and high $\mathrm{pH}$ values than at the isoelectric point. This implies that the maximum value of the specific resistance at the isoelectric point is even more pronounced.

Influence of BSA on the PEG rejection during the filtration of $P E G / B S A$ solutions

In this section the influence of BSA on the PEG rejection during the filtration of PEG/BSA solutions will be discussed. Fig. 7a and Fig. 7b show the PEG rejection with and without the presence of BSA in the solution at $\mathrm{pH}=7.4$ for the inner and outer permeate section, respectively. The results for $\mathrm{pH}=4.5$ are given
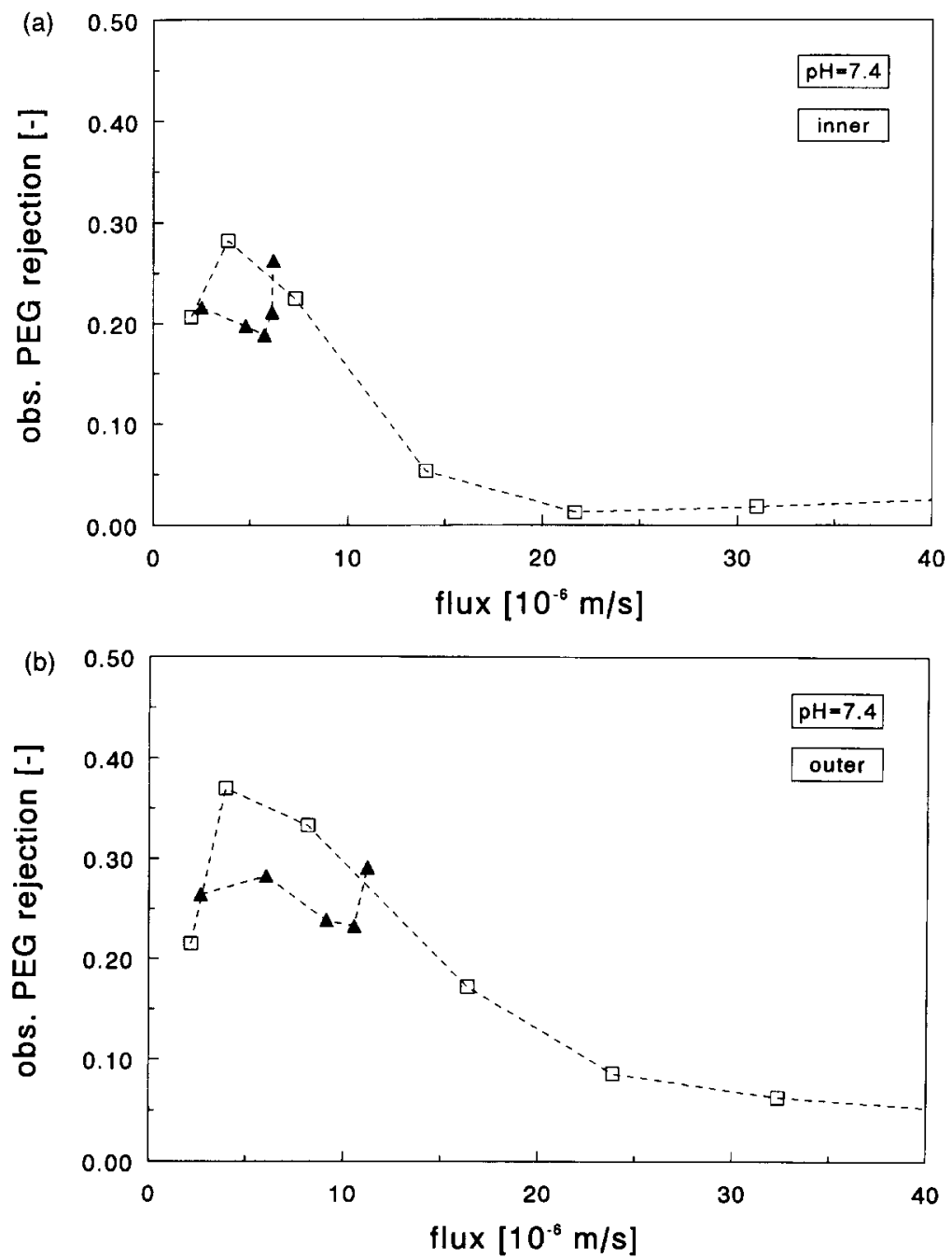

Fig. 7. (a) Observed PEG3400 rejection as a function of the flux on a clean membrane ( $\square$ ) and during the filtration of a $10 \mathrm{~kg} \mathrm{~m}$ BSA +10 $\mathrm{kg} \mathrm{m}^{-3}$ PEG solution ( $\wedge$ ). $n=90 \mathrm{rpm}, \mathrm{pH}=7.4$. Inner section. (b) Idem for the outer section. 

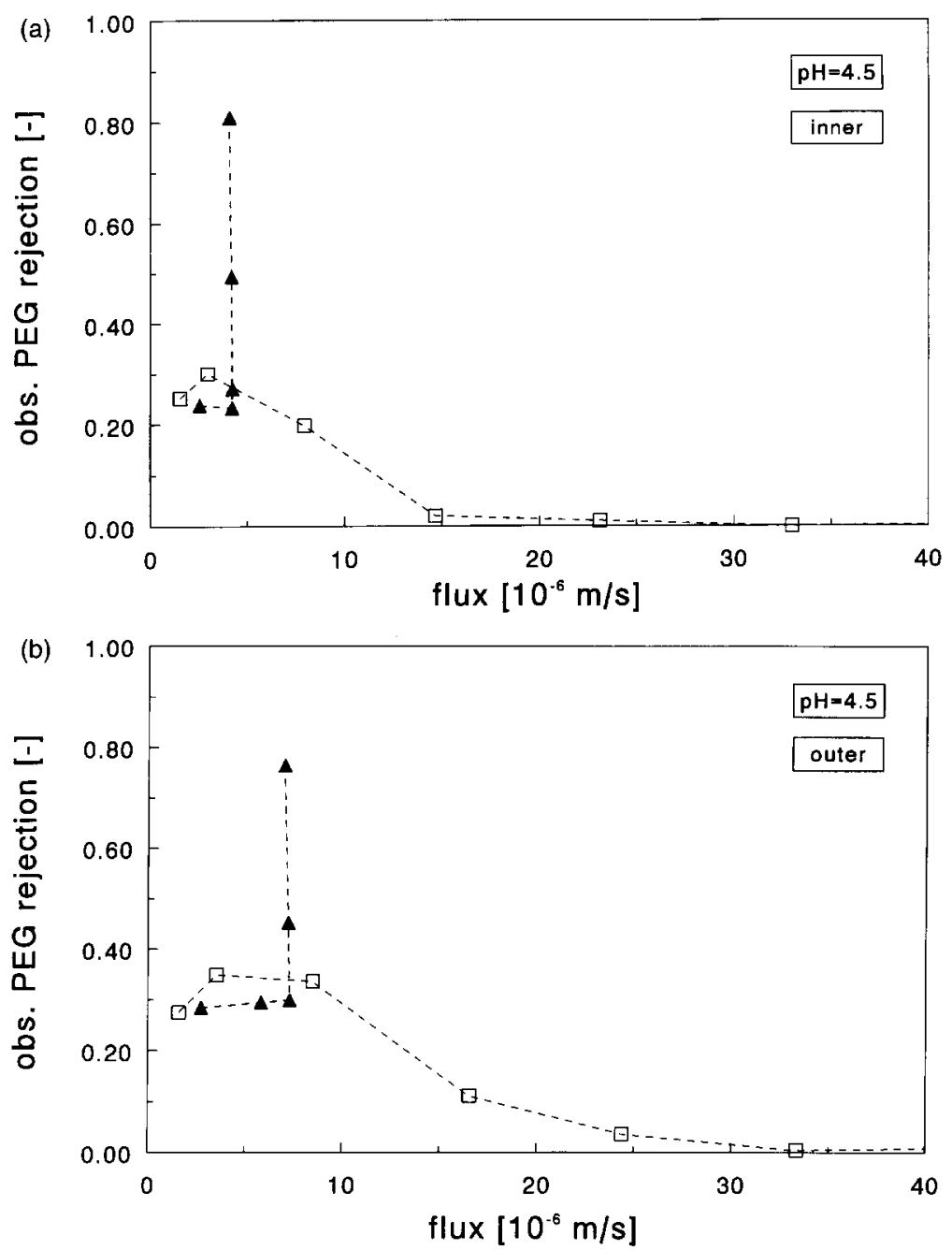

Fig. 8. (a) Observed PEG3400 rejection as a function of the flux on a clean membrane ( $\square$ ) and during the filtration of a $10 \mathrm{~kg} \mathrm{~m} \mathrm{~m}^{-3} \mathrm{BSA}+10$ $\mathrm{kg} \mathrm{m}^{-3} \mathrm{PEG}$ solution ( $\triangle$ ). $n=90 \mathrm{rpm}, \mathrm{pH}=4.5$. Inner section. (b) Idem for the outer section.

in Fig. 8a and Fig. 8b. The corresponding fluxes for the filtration of PEG/BSA are presented in Fig. 9 for both $\mathrm{pH}$ values.

Only a minor change in PEG rejection due to the presence of BSA was found at $\mathrm{pH}=7.4$. Initially, no clear trend can be observed in the difference in PEG rejection with and without $\mathrm{BSA}$. However, for $\mathrm{pH}=4.5$ a strong increase in PEG rejection was measured for both the inner and outer permeate sections. The rise in $P E G$ rejection started from $25 \mathrm{kPa}$ in the inner permeate section and $50 \mathrm{kPa}$ in the outer section. The PEG rejection increased from 0.23 to 0.81 in the inner section and from 0.3 to 0.76 in the outer section. The increase in PEG rejection coincides with the pressure range at which the flux remains constant or even slightly decreases (see Fig. 9). Returning to the values for $\mathrm{pH}=7.4$ it can be noticed that for the inner permeate section the flux limitation occurs at $100 \mathrm{kPa}$. At $\mathrm{pH}=7.4$ an increase in PEG rejection was found as well, but less pronounced than at $\mathrm{pH}=4.5$.

Since the rise in PEG rejection occurs at almost constant fluxes, the cause of the increase seems not to be flux related. An almost constant flux implies that the BSA concentration at the membrane surface hardly changes at higher pressures. Therefore, the increase in $P E G$ rejection cannot be ascribed to an increase in BSA 


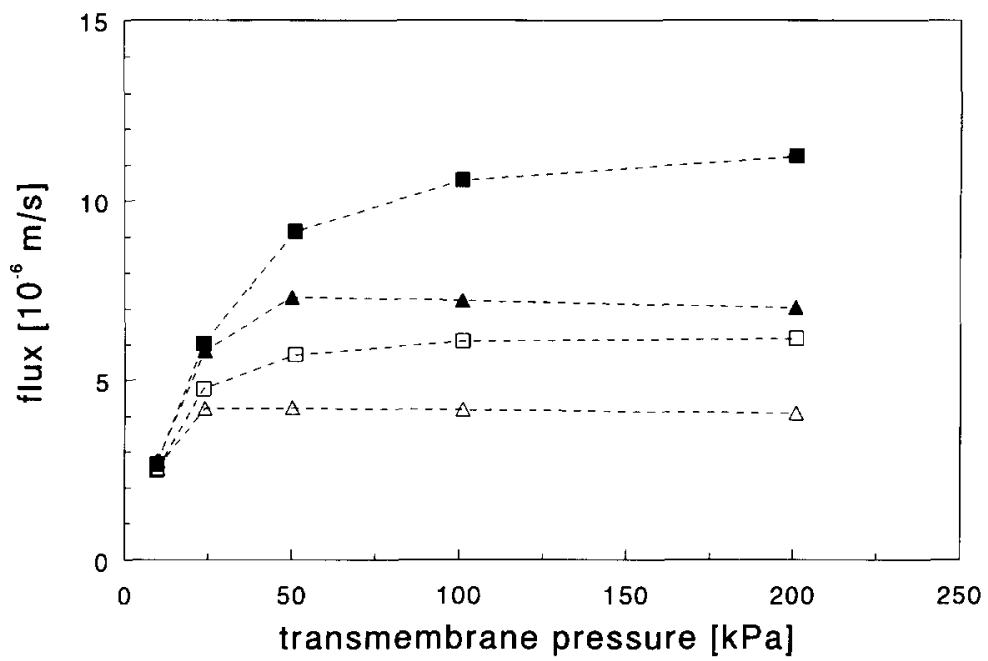

Fig. 9. Flux during the filtration of a $10 \mathrm{~kg} \mathrm{~m}^{-3} \mathrm{BSA}+10 \mathrm{~kg} \mathrm{~m}^{-3} \mathrm{PEG} 3400$ solution as a function of the transmembrane pressure for $\mathrm{pH}=7.4$ ( $\square)$ and $\mathrm{pH}=4.5(\triangle), n=90 \mathrm{rpm}$. Open symbols, inner section; closed symbols, outer section.

concentration at higher pressures. The fact that the PEG rejections in the inner an outer permeate sections have similar values at elevated pressures, although the fluxes differ by more than $50 \%$, points in the direction that the rise in rejection is pressure related. The sharp change from a gradual increasing flux with pressure to a constant or even a slightly decreasing flux (Fig. 9) indicates the formation of a BSA deposit on the membrane surface at higher pressures. This is also confirmed by the saline flux and PEG rejection measurements after the PEG/BSA filtration experiments at 200 $\mathrm{kPa}$ (see previous section). Since the formation of the BSA deposit and the rise in PEG rejection coincide, the former is likely to cause the latter.

The rejection of a component is determined by both the thickness of the deposit and by its exclusion and therefore by the compactness of the deposit. If the osmotic pressure of PEG and BSA does not rise too much, the thickness of the BSA deposit grows with increasing pressure. However, this growth in deposit thickness is not the reason for the increase in PEG rejection as can be concluded from the results of the previous section. In that section it was mentioned that the differences between the saline flux and PEG rejection measurements before and after the PEG/BSA experiment were also the most pronounced at the highest pressures. In those experiments only a PEG solution was filtered through the already present BSA deposit, which means that the thickness of the BSA deposit does not increase with higher pressures as in the PEG/BSA filtration. Thus, in that case the stronger effects at higher pressures can only be ascribed to the compressibility of the deposit. The compaction of the BSA deposit will lead to smaller pore sizes in the deposit and consequently the exclusion of PEG by the deposit layer will increase.

One might argue that additional BSA adsorption might occur during filtration due to the higher BSA concentration at the membrane surface compared to the preadsorption step, which was conducted at the bulk concentration. However, adsorption isotherms tend to flatten at higher concentrations. The adsorption of BSA on the membrane surface is low at $10 \mathrm{~kg} / \mathrm{m}^{3}$. Since the membrane surface will be charged due to the adsorption of BSA it is not expected that at higher BSA concentrations much higher adsorption will be found. As mentioned before, the BSA concentration at the membrane surface hardly changes with higher pressures, which implies that additional adsorption cannot explain the increase in PEG rejection at higher pressures.

The exact thickness of the BSA deposit cannot be accurately determined, because the increase in the membrane resistance due to deposit formation was too small. Without the knowledge of thickness of the BSA deposit the exclusion factor of the BSA deposit cannot be determined from Eq. (3).

Comparing the $\mathrm{PEG}$ rejections at $\mathrm{pH}=4.5$ and 7.4 the rejection of PEG is much more strongly affected at $\mathrm{pH}=4.5$. This confirms the results found after deposition and is due to the higher compactness of the 
deposit layer at $\mathrm{pH}=4.5$ than the one at $\mathrm{pH}=7.4$. No significant difference in PEG rejection was measured between the PEG/BSA filtration after a BSA layer was deposited in a preceding BSA filtration and the direct PEG/BSA filtration.

The fact that the effects on the PEG rejection are more pronounced during the PEG/BSA filtration than when measured for the deposition layer alone after the PEG/BSA filtration could indicate that part of the deposit does not remain on the membrane surface after rinsing. The protein deposit has no strong bonding with the membrane since the membrane resistance recovered its old value after the PEG rejection measurements with the deposit had been performed. This is in contrast with the findings of Opong and Zydney [7] and Mochizuki and Zydney [5] who could perform several experiments with a deposit layer without change of resistance. Sheldon [23] examined replicas of BSA fouled membranes after freeze-fracture and deep-etching and found differences in the nature of the protein layer formed on the separating surface of the polysulfone membrane (PM10) and a regenerated cellulose membrane (YM10). The latter is made of the same material as the membranes used for our study. The protein at the YM10 surface had a similar appearance as the BSA molecules in the solution: a more or less globular structure $(4 \times 4 \times 15 \mathrm{~nm})$. On the other hand, the protein molecules on the polysulfone membranes were long and filamentous and seemed to have unfolded due to the hydrophobic nature of the polysulfone membranes. Since the membranes used by Opong and Mochizuki were made of polyethersulfone it is possible that the protein layers on their membranes differed in structure and persistence from the protein layers on our membranes.

\subsection{Summary of the results for protein deposits}

The adsorption of BSA on the YM30 membrane prior to filtration has no significant influence on the flux or PEG rejection for PEG3400 solutions at both $\mathrm{pH}=7.4$ and 4.5 .

During combined PEG and BSA filtration no deposit layer is formed for the lowest pressures. The deposit formation at $\mathrm{pH}=7.4$ starts at higher pressures than the one at $\mathrm{pH}=4.5$. The protein deposits have no irreversible bonding with the regenerated cellulose membranes, although it takes some time before the value of the saline flux is restored to that prior to BSA filtration. Formation of deposit layers during PEG and BSA filtration increases the rejection of PEG3400. The rise in rejection is the most pronounced at the highest pressures - from 0.25 to 0.8 at $\mathrm{pH}=4.5$ - due to the compressibility of the BSA deposit on the membrane. PEG rejection measurements in the absence and presence of a BSA deposit have shown that the deposits formed at $\mathrm{pH}=4.5$ are more compact than those at $\mathrm{pH}=7.4$. This is most likely due to the closer packing of the BSA molecules at $\mathrm{pH}=4.5$ compared to $\mathrm{pH}=7.4$ because of the lower electrostatic repulsions near the isoelectric point.

\section{Conclusions}

The formation of a thick, open deposit layer on the membrane surface causes a strong decrease in the rejection of other solutes present in the solution, resulting in a total permeation of those solutes. The formation of an open deposit layer, although unfavourable due to the loss in flux, can be used advantageously in the simultaneous concentration and purification of a deposit-forming solute. For purification the rejection of contaminants should be as low as possible. By carefully optimizing the layer thickness, total permeation of the contaminants can be achieved with a minimal loss in flux due to the presence of a deposit layer. If on the other hand both solutes need to be retained, deposit layer formation should be avoided by, for example, lowering the transmembrane pressure, increasing the mass transfer coefficient, or back-flushing.

Proteins tend to form compact, compressible deposit layers on the membrane surface, which increase the rejection of other solutes. To filter at low pressures might prevent protein deposition and lower the compression of the protein deposit, resulting in a smaller increase in the solute rejection. Altering the $\mathrm{pH}$ value can influence the formation of the deposition layer and the compactness of the deposit. If it is the objective to retain the lower molecular solutes in the retentate, the compression of the BSA layer at higher pressures can be used in a positive sense to increase the rejection of the solutes. 


\section{Symbols list}

\subsection{Roman}

C solute concentration $\left(\mathrm{kg} \mathrm{m}^{-3}\right)$

$D \quad$ Fick diffusion coefficient in bulk solution $\left(\mathrm{m}^{2}\right.$ $\mathrm{s}^{-1}$ )

$K$ mass transfer coefficient $\left(\mathrm{m} \mathrm{s}^{-1}\right)$

$n \quad$ stirrer speed $\left(\mathrm{s}^{-1}\right)$

$K_{\mathrm{c}} \quad$ hindrance factor for convection (-)

$K_{\mathrm{d}} \quad$ hindrance factor for diffusion (-)

$P \quad$ pressure $(\mathrm{Pa})$

$\Delta P \quad$ transmembrane pressure $(\mathrm{Pa})$

$P e \quad$ Peclet number (-)

$R_{\text {act }}$ actual rejection (-)

$R_{\text {obs }}$ observed rejection (-)

$R_{\mathrm{m}} \quad$ membrane resistance $\left(\mathrm{m}^{-1}\right)$

$R_{\text {dep }}$ deposit layer resistance $\left(\mathrm{m}^{-1}\right)$

$t$ time (s)

$u_{\text {circ }}$ circulation velocity in tubular membrane ( $m$ $\mathrm{s}^{-1}$ )

$v \quad$ solution velocity, flux $\left(\mathrm{m} \mathrm{s}^{-1}\right)$

$z \quad$ coordinate perpendicular to the membrane surface $(\mathrm{m})$

\subsection{Greek}

$\delta$ thickness $(\mathrm{m})$

$\varepsilon$ porosity $\left(\mathrm{m}^{3} \mathrm{~m}^{-3}\right)$

$\tau$ tortuosity (-)

$\phi$ exclusion factor $(-)$

\subsection{Subscripts}

b bulk

begin start of experiment

$\mathrm{dep} / \mathrm{m}$ at deposit/membrane interface

i inner permeate section

m membrane

o outer permeate section

$\mathrm{p}$ permeate

$\mathrm{r} / \mathrm{dep}$ at retentate/deposit interface

ss steady-state

\subsection{Superscripts}

dep deposit

, in pore liquid inside deposit layer
$" \quad$ in pore liquid inside membrane

\section{Acknowledgements}

Acknowledgements are made to IOP-membranes, Technology foundation, Akzo, Gist-Brocades, Royal Dutch/Shell, Stork Friesland and Unilever for their financial support. We thank K. Meeuwsen, L. Xu, F. Panneflek and R. Kuijpers for their contributions to this work.

\section{References}

[1] S. Nakao, S. Yumoto and S. Kimura, Analysis of rejection characteristics of macromolecular gel layer for low molecular weight solute in ultrafiltration, J. Chem. Eng. Jpn., 15 (1982) 463.

[2] S. Kimura, T. Ohtani and A. Watanabe, Nature of dynamically formed ultrafiltration membranes, ACS Symp. Ser., 281 (1985) 35 .

[3] M. Meireles, P. Aimar and V. Sanchez, Effects of protein fouling on the apparent pore size distribution of sieving membranes, J. Membrane Sci., 56 ( 1991 ) 13.

[4] S. Mochizuki and A.L. Zydney, Effect of protein adsorption on the transport characteristics of asymmetric ultrafiltration membranes, Biotechnol. Prog., 8 (1992) 553.

[5] S. Mochizuki and A.L. Zydney, Sieving characteristics of albumin deposits formed during microfiltration, J. Colloid Interface Sci., 158 ( 1993 ) 136.

[6] N. Papamichael and M.R. Kula, A hydrodynamic study of the retention of polyethylene glycols by cellulose acetate membranes in the absence and presence of proteins, J. Membrane Sci., 30 ( 1987) 259.

[7] W.S. Opong and A.L. Zydney, Hydraulic permeability of protein layers deposited during ultrafiltration, J. Colloid Interface Sci., 142 ( 1991 ) 41

[8] T.F. Busby and K.C. Ingham, Separation of macromolecules by ultrafiltration: removal of poly(ethylene glycol) from human albumin, J. Biochem. Biophys. Methods, 2 (1980) 191.

[9] K.C. Ingham, T.F. Busby, Y. Sahlestrom and F. Castino, Separation of macromolecules by ultrafiltration: influence of protein adsorption, protein-protein interactions and concentration polarization, in A.R. Cooper (Ed.), Proc. Symp. Ultrafiltration Membranes Applications, Washington DC, 9 14 September 1979.

[10] S. Lentsch, P. Aimar, J. Orozco, Enhanced separation of albumin-poly(ethylene glycol) by combination of ultrafiltration and electrophoresis, J. Membrane Sci., 80 (1993) 221.

[11] P.J.A.M. Kerkhof and G.H. Schoutens, Membrane processing of industrial enzymes, in S. Bruin (Ed.), Preconcentration and Drying of Food Materials, Elsevier, Amsterdam, 1988, p. 87. 
[12] A.G. Suki, A.G. Fane and C.J.D. Fell, Flux decline in protein ultrafiltration, J. Membrane Sci., 21 ( 1984) 269.

[13] S.P. Palecek, S. Mochizuki and A.L. Zydney, Effect of ionic environment on BSA filtration and the properties of BSA deposits, Desalination 90 (1993) 147.

[14] J. Jagur-Grodzinski and O. Kedem, Transport coefficients and salt rejection in unchanged hyperfiltration membranes, Desalination, 1 (1966) 327.

[15] W.M. Deen, Hindered transport of large molecules in liquidfilled pores, AlChE J., 33 (1987) 1409.

[16] W.C.M. Henkes and J.A.M. Smit, Salt rejection and flux in reverse osmosis with compactible membranes, Desalination, 28 (1979) 65.

[17] H.R. Ridgway, Jr., Microcial adhesion an biofouling of reverse osmosis membranes, Chem. Ind. Reverse Osmosis Technol., 35 ( 1988$) 429$.

[18] C.W. van Oers, M.A.G. Vorstman, W.G.H.M. Muijselaar and P.J.A.M. Kerkhof, Unsteady state flux behaviour in relation to the presence of a gel layer, J. Membrane Sci, 73 (1992) 231.

[19] E.A. Tsapiuk, M.T. Bryk, V.M. Kochkodan and E.E. Danilenko, Separation of aqueous solutions of nonionic organic solutes by ultrafiltration, J. Membrane Sci., 48 (1990) 1.
[20] C.W. van Oers, Solute Rejection in Multicomponent Systems During Ultrafiltration, Ph.D. Thesis, Eindhoven University of Technology, The Netherlands, 1994.

[21] R.K. Iler, The Chemistry of Silica, Wiley, NY, 1979.

[22] E. Matthiasson, The role of macromolecular adsorption in fouling of ultrafiltration membranes. J. Membrane Sci., 16 (1983) 23.

[23] J.M. Sheldon, The fine structure of ultrafiltration membranes. II. Protein fouled membranes, J. Membrane Sci., 62 (1991) 87.

[24] M.W. Chudacek and A.G. Fane, The dynamics of polarisation in unstirred and stirred ultrafiltration, J. Membrane Sci., 21 (1984) 145.

[25] W.S. Opong, Protein Transport and Deposition During Sizeselective Membrane Filtration, Ph.D. Thesis, University of Delaware, Wilmington, DE, USA, 1991.

[26] B.C. Robertson and A.L. Zydney, Protein adsorption in asymmetric ultrafiltration membranes with highly constricted pores, 134 ( 1990) 563.

[27] A.L. Zydney, Personal communication, 1993. 